\title{
Analysis of person-situation interactions in educational settings via cross-classified multilevel longitudinal modelling: illustrated with the example of students' stress experience
}

\author{
Tobias Kärner $^{\mathrm{a} 1}$, Detlef Sembill ${ }^{\mathrm{a}}$, Christian Aßmann ${ }^{\mathrm{b}}$, Edgar Friederichs ${ }^{\mathrm{a}}$, and \\ Claus H. Carstensen ${ }^{\mathrm{c}}$
}

\author{
${ }^{a}$ Chair of Economics and Business Education, University of Bamberg, Germany \\ ${ }^{\mathrm{b}}$ Chair of Statistics and Econometrics, University of Bamberg, Germany \\ ${ }^{c}$ Chair of Psychology and Methods of Educational Research, University of Bamberg, Germany
}

Article received 9 December / revised 13 October / accepted 16 November / available online 10 February

\begin{abstract}
The investigation of learning processes by assessing students' experience along with objective characteristics within a classroom context has a long tradition in empirical learning process research (e.g. Sembill, 1984 et passim; Wild \& Krapp, 1996). However, most of the existing studies confine themselves to psychological variables that seem to be too narrowly considered, as there is theoretical and empirical evidence proving the involvement of somatic and psychological processes in learning and in stress reactions. Furthermore there is a lack of studies that investigate situation-related experience (states) as an outcome of interactions between relatively stable characteristics (traits) and continuously changing "objective" context conditions. Against this background, we will present an approach for cross-classified multilevel longitudinal modelling of person-situation interactions in naturalistic educational settings. We illustrated our model with the example of students' stress experience referring to empirical data that we measured within a multidisciplinary research project (pedagogy, psychology, adolescent medicine). 53 students at a public German vocational school were investigated during 9 lessons. There are up to 38 state measurements per person, resulting in 2,014 measurements in total. Taking into account that states are nested within persons and within situations we applied a cross-classified multilevel model to analyse effects on students' stress experience. The analysis shows significant person-situation interactions between academic self-concept and classroom demands and between baseline cortisol concentration and classroom demands: the relation between classroom demands and stress experience depends on relatively stable person-related characteristics. A deeper knowledge about the complex interrelations between traits, states, and continuously changing context conditions seems to be essential for a more holistic understanding of learning at school and for the identification of crucial aspects for an evidence-based design and implementation of teaching and learning arrangements.
\end{abstract}

Keywords: Learning process research; Experience sampling; Video analysis; Classroom demands; Stress; Cortisol; Heart rate variability; Academic self-concept

\footnotetext{
${ }^{1}$ Contact information: Tobias Kärner, Chair of Business Education and Educational Management, University of Bamberg, Kärntenstraße 7, 96052 Bamberg, Germany. Email: tobias.kaerner@uni-bamberg.de DOI:

http://dx.doi.org/10.14786/flr.v5i1.137
} 


\section{Introduction}

School, as an essential part of adolescents' learning environments, involves a number of potential stressors that increase individual chances of stress reactions. Difficulty of learning material, time pressure, and pressure to succeed have been noted as potential school-related stressors (e.g. Achtenhagen, 1978; Kouzma \& Kennedy, 2004). Stress is not a one-, but a multi-dimensional phenomenon, as psychological and somatic processes constituting a complex system of relations are involved (Adam, 2006; Kemeny, 2003). Various existing studies pursue top-down approaches in order to translate psychological constructs into basic physiological mechanisms (e.g. Michaud et al., 2008; Roubinov et al., 2012; summarizing Ellenbogen, 2012); fewer studies consider a bottom-up approach assessing the effects of physiological variables on psychological variables (e.g. Buchanan \& Lovallo, 2001). The present study assumes that students' stress experience is affected by physiological and psychological characteristics, situation-specific states, and "objective" characteristics of the classroom context. Furthermore, we have to consider the interactions between person and classroom context, which play an important role in students' stress responses. In that regard, stress is seen as a specific relationship between person and environment, and more specifically, as an interrelationship between situational demands and personality characteristics (Lazarus, 1966 et passim). Here, internal or external demands that tax or exceed one's adaptive resources may lead to stress reactions that involve psychological and somatic systems (Lazarus, 1999).

The referred paradigm is known as "interactionism" and focuses on the relationship between individuals, with their relatively stable characteristics, and the objective context-specific characteristics. This relationship is supposed to manifest itself in situation-related experience and in specific behaviours (Carver \& Scheier, 2008; Nezlek, 2007). In an educational context, the interactional perspective is discussed within the scope of aptitude (trait) treatment interaction (ATI) theory. ATI theory assumes that a specific outcome (e.g. behaviour, experience) depends on the interaction between students' traits and the characteristics of the classroom context they are exposed to (Cronbach \& Snow, 1977; Snow, 1989; Yeh, 2012). Existing research on trait-treatment interactions is mostly based on cross-sectional methods within laboratory studies that do not account for longitudinal processes in naturalistic learning environments. Therefore, in the current paper we use a multilevel longitudinal approach to examine continuously changing conditions in the classroom (especially demanding conditions during the lessons) along with students' experience.

\section{Background}

Before stating our research aims and hypotheses, we will provide some information about the background of the referred approaches and constructs that are related to students' stress response. Here, we first introduce the hypothalamic-pituitary-adrenal axis and the sympathetic and parasympathetic nervous system, afterwards presenting some information about the connection between traits (specifically academic self-concept as an important coping resource) and situational experience, finally looking at potential classroom demands.

\subsection{Hypothalamic-pituitary-adrenal axis activity}

Stress induction leads to an activation of the hypothalamic-pituitary-adrenal (HPA) axis (e.g. Michaud et al., 2008). This activation is initiated by a secretion of corticotropin-releasing hormone, which stimulates the anterior pituitary gland. In turn, this involves a secretion of adrenocorticotropic hormone that enters the blood circulation, triggering the adrenal cortex to release the glucocorticoid cortisol (Dickerson \& Kemeny, 2004; Kemeny, 2003). A typical pattern of cortisol concentration 
exists during the day that corresponds to a circadian rhythm and ideal-typically accords to an inverted U-shaped curve. Various studies show that individual baseline cortisol concentration is an indicator for chronic stress (e.g. Caplan et al., 1979; Pruessner et al., 2003; Takahashi et al., 2005). Cortisol concentration is normally high in the morning and low in the evening; therefore, potential energy is expended during (things like) coping processes throughout the day (Hall, 2011). Wüst et al. (2000) found that the awakening cortisol response is significantly associated with perceived chronic stress. Takahashi et al. (2005) identified a significant positive correlation between individual trait anxiety and baseline cortisol concentration $(r=.58)$ and a positive but non-significant correlation between state anxiety and baseline cortisol concentration $(r=.25)$. The authors conclude that individuals "with chronic high levels of cortisol may have blunted acute neuroendocrine response to experimental social stress, possibly due to saturated HPA reactivity" (Takahashi et al., 2005, p. 353). In endocrinological studies, a frequently used method for assessing overall secretion of cortisol over a specific time period is the "area under the curve with respect to the ground" (AUCg) (Pruessner et al., 2003; for details see section "4.2.1 Baseline cortisol concentration"). There is theoretical and empirical evidence that AUCg is related to chronic stress, but current research shows that high chronic stress levels are not always associated with elevated baseline cortisol. Differences in found empirical relations between AUCg and chronic stress may result from methodological, theoretical, and analytical issues (for a further discussion see Saxbe, 2008).

\subsection{Sympathetic and parasympathetic activity}

Another somatic system involved in human stress reactions is the autonomic nervous system, which ensures - compared to the reaction of the HPA axis - a much more rapid adaptation to stressful situations. It contains two essential components (Baert et al., 2012): on the one hand, the parasympathetic nervous system, controlling physiological resting functions; and on the other hand, the sympathetic nervous system, which is primarily activated under stress (Kemeny, 2003). As one indicator of sympathetic and parasympathetic activity, the activity of the cardiovascular system, particularly heart rate variability, is taken into account as an important marker. Within the frequency spectrum, the parasympathetic component of the autonomic nervous system is reflected by high frequency domain (HF); the activity of the sympathetic nervous system by low frequency domain (LF) (Agelink et al., 2001; Malik et al., 1996). The LF/HF ratio, as a frequency-based indicator of heart rate variability, reflects the sympathovagal balance (Sleight \& Bernardi, 1998). Various studies report a significant increase of the LF/HF ratio in experimental stress situations that is caused by a decrease of the HF component (compared to the LF component), that in turn indicates a predominant state of the sympathetic nervous system under stress (Baert et al., 2012; Hjortskov et al., 2004; Isowa et al., 2006). HPA axis and autonomic nervous system are related (Kemeny, 2003); Stadler et al. (2011) as well as Looser et al. (2010) found significant correlations between heart rate variability and cortisol awaking response. Looser et al. (2010) suppose "a relative independence in the regulation of the HPA axis and the automatic nervous system in response to everyday stressors but synchrony of both systems in highly stressful situations" (p. 281).

\subsection{Coping resources and situational experience}

Lazarus (1966) describes traits as relatively stable personal characteristics. The term "relatively stable" means that traits can indeed change over longer periods of time (e.g. three years) but remain quite stable over a defined time period (e.g. three months) (Nezlek, 2007). On the other hand, psychological states - in terms of situational experience - are situation-specific and transient. In reference to the transactional model of stress and coping, it has to be taken into account that stress results from subjective appraisal of a stressful or demanding situation and the situational coping within the current situation. Here, subjective appraisal implies emotional processes involving cognitiveaffective states and physiological processes (Lazarus, 1984; Lazarus \& Folkman, 1984). 
An important trait variable is the academic self-concept, which describes a person's perception of his performance-related self-identity. As a construct that refers to mastery experience as a major information source, it is similar to the construct of self-efficacy beliefs (Bong \& Skaalvik, 2003). Academic self-concept is not merely a cognitive construct. It also integrates motivational and emotional aspects (Shavelson et al., 1976) and mediates appraisal and coping processes, thus causing it to be seen as an important coping resource (Goetz et al., 2008). Within this context, coping is defined by Lazarus and Folkman (1984) as "constantly changing cognitive and behavioural efforts to manage specific external and/or internal demands that are appraised as taxing or exceeding the resources of a person" (p. 141). Characteristics like academic self-concept may affect emotional, cognitive, and motivational states (Sembill, 2004; Sembill et al., 2002). There are direct as well as indirect relationships between traits and states; coping processes mediate this relationship (Spangler et al., 2002).

Regarding the different ontological levels involved in human stress reactions (cf. Sembill, Rausch, \& Kögler, 2013), relationships also exist between the psychological level and adrenocortical responses (Adam, 2006). Spangler et al. (2002) for example report an interaction between trait anxiety and the development of cortisol concentration during an exam situation. A significant increase in cortisol was revealed amongst high anxiety students. On the other hand, a significant decrease was reported in low anxiety students. These results are congruent to the study of Takahashi et al. (2005). The authors summarise that "high trait anxiety [... is] associated with chronic elevation in the level of HPA activation" (p. 353). In addition there are significant negative correlations between emotionoriented coping and cortisol concentration ( $r=-.38$ and $r=-.44$, see Spangler et al., 2002).

\section{$2.4 \quad$ Classroom demands}

Current research lacks examples of well-founded empirical evidence for the stress-triggering potential of various aspects of the classroom context. Here, it is necessary to consider the main effects of classroom context characteristics on students' stress experience and to take into account traittreatment effects.

Main effects of classroom characteristics on students' stress experience may result from aspects of the didactical design of the lessons. In regard to learning processes, empirical studies show that student-centred learning strongly supports higher levels of motivation and increased competence in complex problem-solving within students. Moreover, student-centred learning results in increased self-determination (Deci \& Ryan, 1985; Schunk \& Zimmerman, 1994; Seifried, 2004; Sembill et al., 2002). However, in terms of "learning with risk" according to Sembill et al. (2002), in student-centred periods learners may also be confronted with higher degrees of complexity regarding domain-specific learning material, uncertainty, ambiguity, time pressure or public-speaking situations that may be stressful for them.

Furthermore, main effects of classroom characteristics on students' stress experience may result from the complexity of learning contents and from the associated cognitive challenge of handling a given learning material. This in turn may result in demands on the information system, specifically on the working memory capacity. In that regard, Sweller and colleagues differentiate between intrinsic cognitive load and extraneous cognitive load. Intrinsic cognitive load is associated with the structure of the information that is necessary for students to reach their learning goals. Task difficulty, informational complexity, and the perceived understanding of the learning content play an important role in considering to what extent the student perceives the learning material to be demanding and stressful (Sweller, 1988; 1994). The complexity of learning contents within the classroom context can be described via Bloom's taxonomy of learning objectives providing a hierarchical classification of the cognitive challenge of handling a given learning material (such as "applying", "analysing", "synthesizing", and "evaluating"; Bloom et al., 1956). The extraneous cognitive load also requires working memory resources and is associated, not with the intrinsic 
structure of the processed information, but with the learning activities in which students have to engage (Sweller, Ayres, \& Kalyuga, 2011). Here, student-centred learning in particular is associated with a high degree of cognitive challenge during education that is characterised by complex tasks and active student engagement (Rieser et al., 2013). We assume that when taken together, the amount of student-centred learning and the level of cognitive challenge when handling a given learning material constitute demanding conditions for students.

Besides main effects of classroom characteristics on students' stress experience, one has to also take trait-treatment effects into account. Whether a task or an activity is perceived as demanding or stressful depends not only on the objective conditions in class, but also to a great extent on the individual's disposition. In that regard, Krohne (1990, p. 27) states that the "process of cognitively transforming objective characteristics into subjective representations is clearly codetermined by personality dispositions" such as coping dispositions or control expectancies. The referred theoretical concept is known as the "interactional paradigm" and can be found in personnel psychology in terms of person-organisation-fit models (Kristof-Brown, Zimmerman, \& Johnson, 2005). In clinical and developmental psychology, the aforementioned paradigm is discussed in terms of the diathesis-stress model. It describes (psychopathological) development as a result of an interaction between predispositional vulnerability and stressful context conditions: the higher the vulnerability, the greater the responsiveness to stressful conditions (Belsky \& Pluess, 2009). In educational psychology, the corresponding approach is known as aptitude (trait) treatment interaction theory (Cronbach \& Snow, 1977; Snow, 1989) and has been extensively investigated in the context of anxiety research (Spielberger, 1989). The corresponding state-trait (interaction) model of anxiety postulates combined effects of individual differences in trait anxiety and objective situational conditions in terms of the type of threat on state anxiety response (Shedletsky \& Endler, 1974): persons with high trait anxiety values show greater state anxiety reactions under stress than persons with low trait anxiety values (Kendall, 1981).

\section{Research aims and hypotheses}

Existing research on students' stress responses mostly refers to cross-sectional (laboratory) studies but show a lack of longitudinal studies specifically considering naturalistic learning processes at school. Ellenbogen (2012) points out that one of the most important challenges in this context is closing the gap between laboratory research and naturalistic studies. Further, few studies exist that analyse different levels of stress- and coping-related systems and processes simultaneously (e.g. Adam, 2006; Beck \& Sczesny, 1993; Goetz et al., 2008). In that regard, there is a lack of studies assessing psychological and physiological states in naturalistic learning environments and taking special account of continuously changing context conditions assessed during class via objective observational methods. Based on the described considerations, we consider the following research question and hypotheses:

To what extent is students' stress experience associated with baseline cortisol concentration, academic self-concept, heart rate variability (LF/HF ratio), situational coping, and classroom demands?

(1) It will be hypothesised that the baseline cortisol concentration and the LF/HF ratio are positively associated with students' stress experience (cf. Baert et al., 2012; Hjortskov et al., 2004; Isowa et al., 2006; Takahashi et al., 2005) and that academic self-concept and situational coping are negatively related to students' stress experience (cf. Goetz et al., 2008; Spangler et al., 2002). 
(2) With respect to the classroom context we hypothesise that classroom demands are positively associated with students' stress experience (cf. Sembill et al., 2002; Sweller, 1988; 1994).

(3) Furthermore, we hypothesise that there are person-situation interactions between baseline cortisol concentration and classroom demands, as well as between academic self-concept and classroom demands, as follows:

a) Persons with high baseline cortisol values should show a greater stress-response under high degrees of classroom demands than persons with low baseline cortisol values, as high cortisol baseline values are associated with physiological vulnerability-as a possible result from accumulated chronic stress - that should affect the relationship between stressful context conditions and stress experience (cf. Belsky \& Pluess, 2009; Takahashi et al., 2005; Wüst et al., 2000);

b) Persons with high academic self-concept values should show a lower stress response under high degrees of classroom demands than persons with low academic self-concept values, as a person's self-related perception of his/her coping abilities is seen as a substantial resource against external demands (cf. Lazarus \& Folkman, 1984; Goetz et al., 2008).

\section{Method}

\subsection{Participants and data collection}

Within a short-term longitudinal study, students from a public German vocational training school were investigated during 9 school lessons on the subject "economic business processes". The sample was composed of 53 students (18 male, 35 female) within two classes and with a mean age of 19.53 years $(S D=4.76)$. The study was approved by the Bavarian Ministry of Education and Cultural Affairs and was conducted in accordance with the Declaration of Helsinki. Participants were of full age, and if they were not, the parents of the underage participant signed declarations of consent prior to participating.

Our study was designed to investigate effects of individual preconditions and characteristics within the classroom context on students' states during learning processes (see Figure 1). Before investigating the lessons in school we measured academic self-concept and baseline cortisol concentration. Two months later, during the following learning processes we measured the students' experience during the lessons along with their cardiovascular activity. We also recorded the lessons for subsequent video-based analysis of classroom characteristics (especially classroom demands).

\begin{tabular}{|c|c|}
\hline $\left.\begin{array}{l}\text { Data collection before the } \\
\text { learning processes }\end{array}\right\rangle \begin{array}{c}\text { two months } \\
\text { interim } \\
\text { period }\end{array}$ & $\begin{array}{l}\text { Data collection during the } \\
\text { learning processes }\end{array}$ \\
\hline * Academic self-concept & * Continuous sampling of students' experience \\
\hline \multirow{2}{*}{$\begin{array}{l}\text { * Baseline cortisol concentration } \\
\text { (8:00a.m./12:00noon/16:00p.m./20:00p.m.) }\end{array}$} & * Cardiovascular activity (LF/HF ratio) \\
\hline & * Video-based observation of classroom demands \\
\hline
\end{tabular}

Figure 1. Data collection 


\subsection{Measures and operationalisation}

\subsubsection{Baseline cortisol concentration}

Baseline cortisol concentration was measured using biochemical salivary analysis. The students received small plastic tubes and were instructed to provide saliva samples during a relaxed weekend day without school or work at the following times: 8:00 a.m., 12:00 noon, 16:00 p.m., and 20:00 p.m. The saliva samples were immediately transported to a laboratory that performed the analysis (Immumed Ltd., Institute for applied Immunology, Munich, Germany), carried out via a laboratory machine by Roche Diagnostics ${ }^{\circledR}$. An electrochemiluminescence immunoassay was applied to measure the concentration of salivary cortisol. With a correlation of $r=.94$, the general test-retest reliability of cortisol measures defined by repeated measurements carried out via Elecsys $2010 \AA$ was found to be acceptable (Cobas, 2010). Testing for reliability we calculated Cronbach's alpha coefficient for reliability over the four measures of cortisol and found a satisfactory interrelationship $(\alpha=.86)$.

As we wanted to assess the chronic elevation of HPA activation by considering multiple data points, we used the individual areas under the curves with respect to the ground (AUCg) for assessing baseline cortisol secretion, a common method used to derive information from multiple measures over time (Pruessner et al., 2003). AUCg indicates the total area under the curve of all cortisol measures over the day. Fekedulegn et al. (2007) point out that AUCg takes into account the sensitivity and the intensity of multiple measurements of cortisol. Furthermore, it acts as an indicator for the "total hormone output" (Pruessner et al., 2003, p. 928). For calculating the individual areas under the curves, we used the trapezoid formula for the area under the curve with respect to the ground following Pruessner et al. (2003), with identical periods of time in between taking the measurements (Eq. 1):

$$
\text { AUCg }=\sum_{i=1}^{n-1} \frac{\left(m_{(i+1)}+m_{i}\right)}{2}
$$

with $m_{i}$ denoting the individual measurement and $n$ denoting the total amount of measures. Overall we found a mean AUCg of $M=10.21(S D=7.96$, Min. $=.75$, Max. $=40.42)$ in the current sample that shows a marked variability.

\subsubsection{Heart rate variability (LF/HF ratio)}

Heart rate variability was measured via equipment from Medeia Ltd. ${ }^{\circledR}($ Danev, 2010) and was operationalised by the LF/HF ratio (with LF from .04 Hz to $.15 \mathrm{~Hz}$ and $\mathrm{HF}$ from $.15 \mathrm{~Hz}$ to $.4 \mathrm{~Hz}$; cf. Agelink et al., 2001; Malik et al., 1996). The cardiovascular activity of the students was continuously measured during the investigated lessons. For further analysis, the LF/HF ratio measures were aggregated per person at 10-minute intervals via arithmetic means to synchronise the LF/HF ratio measures with psychological states and context conditions. The students received chest belts and storage devices that recorded the cardiovascular activity data wirelessly on an integrated memory chip (cf. Danev, 2010). LF/HF ratio was calculated via the software Qhrv Assessment (Medeia Ltd. ${ }^{\circledR}$ ) resulting in an overall LF/HF ratio of $M=1.07(S D=.32$, Min. $=.41$, Max. $=3.22)$.

\subsubsection{Academic self-concept}

Academic self-concept was measured via six items that were adopted from Rost et al.'s (2007) Scale for assessing Self-concept of School related Achievement and Skills (SKSLF-8, e.g. "It's easy for me to resolve problems in school"). Learners rated items on a six-point Likert-type scale $(1=$ "Strongly disagree", 6 = "Strongly agree"). The six self-concept items were averaged to a total scale, demonstrating satisfactory reliability $(\alpha=.81 ; M=4.05, S D=.78$, Min. $=2.17$, Max. $=5.67)$. 


\subsubsection{Students' experience during class}

Students' stress experience and situational coping were sampled at 10-minute intervals using mobile handheld-computers (Palm Tungsten E2®). The continuous-state-sampling method used (Sembill et al., 2002; Sembill, Seifried, \& Dreyer, 2008) offers a high degree of ecological validity and differs from other experience-sampling methods (e.g. Csíkszentmihályi \& Larson, 1987) due to the high frequency of its measurements and the equidistance of its measurement points, as the data are not sampled at randomly chosen times. There are a maximum number of 38 measurement points per person in the current study, adding up to a cumulative total of 2,014 measures. The number of measurement points equals the quantity of physiological states (LF/HF ratio) measures. For further analysis, physiological and psychological states were chronologically synchronised.

Students had the opportunity to rate their actual experience on a continuous rating scale from 0 (= "I fully disagree") to 100 (= "I fully agree"). The scale referred to is comparable to the visual analogue mood scale from Luria (1975) and has been proved to be successful in previous processrelated video studies of the research group, for example in the field of self-organised learning (e.g. Sembill et al., 2002). Situational coping (SC) was measured using two items ("I can cope with actual demands", $M=75.40, S D=21.19$, Min. $=0$, Max. $=100$; "I understand subject matter", $M=79.80$, $S D=20.06$, Min. $=0$, Max. $=100)$. Students' stress experience $(\mathrm{SSE})$, the dependent variable in our analysis, was measured via two items ("I'm under time pressure", $M=17.44, S D=25.01$, Min. $=0$, Max. $=100$; "I'm under pressure to succeed", $M=20.62, S D=25.43$, Min. $=0$, Max. $=100$ ). The items were formulated by the research group with regard to perceived time pressure and pressure to succeed as frequently mentioned terms for school related stressors (e.g. Kouzma \& Kennedy, 2004) and to subjective coping competence and situational understanding as indicators for self-confidence in ability to follow the lesson (Kärner, 2015; Sembill et al., 2002). Assessing the factorial structure of the four items, we applied an exploratory factor analysis with varimax rotation and referred to the Kaiser criterion (eigenvalue $>1$ ). The items form a two-factor solution that accounts for $85.29 \%$ of the total variance (compared to the one-factor solution, accounting for only $43.17 \%$ ). Both items relating to students' stress experience $(\mathrm{r}=.73)$ and both items of situational coping $(\mathrm{r}=.68)$ are correlated moderately to each other. For further analysis we used the factor scores as estimated values of the factors "situational coping" and "students' stress experience".

\subsubsection{Classroom demands}

Classroom demands-as "objective" characteristics of the classroom context-were operationalised by the amount of student-centred learning and by the quality of cognitive challenge during education. Student-centring is defined by phases of individual or group work where learners work independently from the teacher on complex problems. It was assessed via video-based timesampling analysis using a defined category-system we adopted from Seidel et al. (2001). Time intervals of 15 seconds each were coded. Afterwards, the single coded 15-second intervals were aggregated to 10-minute intervals via sum scores, synchronising the context conditions-in terms of "micro-segments" of classroom context-and the person-related data. To assess the reliability of the codings, one third of the videos were coded by two independent coders, finding a satisfactory Cohen's kappa of .73. Overall we found a mean of $M=3.16$ minutes $(S D=3.63$, Min. $=0$, Max. $=9.5)$ studentcentring per 10 minutes of education.

Cognitive challenge during class was coded by ratings of two independent coders: they coded one third of the videos (between-coder-correlation $r=.82$ ) on the basis of the observed classroom discussion and the learning material the students worked on. In order to assess content-related difficulty, we referred to the curriculum of the corresponding subject "economic business processes" and to Bloom's taxonomy of learning objectives. Time intervals of 1 minute each were coded, and we used a four point Likert-type scale based on Bloom's taxonomy to assess the complexity of learning contents $(0=$ "applying", 1 = "analysing", 2 = "synthesizing", 3 = "evaluating"; cf. Bloom et al., 
1956). Afterwards, the single coded 1-minute intervals were arithmetically aggregated to 10 -minute intervals. An overall mean of $M=1.50(S D=.82$, Min.$=.44$, Max. $=3.00)$ of cognitive challenge in the observed lessons was found. Assessing the factorial structure of the amount of student-centred learning and the cognitive challenge during education, we applied an exploratory factor analysis with varimax rotation and referred to the Kaiser criterion (eigenvalue $>1$ ). The items form a one-factor solution that accounts for $87.55 \%$ of the total variance, with both variables correlated moderately to each other $(r=.75)$. Afterwards, we used the factor scores as estimated values of the factor "classroom demands".

\subsection{Statistical analysis}

\subsubsection{Previous analysis}

Pearson product-moment correlations were calculated in order to identify multicollinearity and to check characteristics of the independent variables.

\subsubsection{Multilevel analysis}

Against our theoretical background, it seems to be crucial to measure time-varying states and objective context conditions in a synchronic way in addition to relatively enduring characteristics. Appropriate interrelationships can be investigated using multilevel analytic methods, as they provide the opportunity to simultaneously analyse different hierarchical data levels. In this context, longitudinal data can be seen as hierarchical data, with repeated measurements nested within persons (Bryk \& Raudenbush, 1992; Goldstein et al., 1994; Heck \& Thomas, 2009; Hox, 2002; Nezlek, 2007). Scollon et al. (2003) point out that multilevel modelling is useful in analysing continuously sampled data because multiple data points are nested in a single individual. In our case, students' states are not only nested within persons but also within situations that are defined as "micro-segments" of the classroom context prevailing at the time of measurement. Therefore we applied a cross-classified multilevel model (cf. Heck et al., 2010). Cross-classification considers that the multiple state-measures are not only nested within persons but that they also belong to observation units of the classroom context at Level 2 corresponding to the time of measurement (cf. Goldstein, 1994; Hill \& Goldstein, 1998). Most of the existing approaches in researching person-situation interactions analyse how variations in situations affect individuals depending on their dispositions via analysis-of-variance or multivariate regression analysis (Carver \& Scheier, 2008; Cronbach \& Snow, 1977). But these approaches do not usually consider the hierarchical data structure implied by multiple measures, that is important because investigating trait-treatment interactions should focus on analysing how persons show changes in an outcome variable over time or across situations (Yeh, 2012). Multilevel methods have the advantage of combining the different approaches within a simultaneous analysis, therefore providing a potential method for investigating person-situation interactions in the classroom context (cf. Nezlek, 2007). In our analysis, the hierarchical data structure is reflected in the variables as follows.

a) Level 3 represents the CLASS level: While the teachers of the two classes in our sample dealt with the same subject ("economic business processes") within the same time frame, an ANOVA shows that the two classes differ in general levels of classroom demands: class $a(M=-.52, S D=.48)$ demonstrates a lower degree of classroom demands than class $b(M=.59, S D=1.12)\left[F(1,74)=31.48, p<.001, \eta^{2}=.298\right]$. Therefore, we consider the class-related means of classroom demands as a Level 3 variable.

b) On the one hand, Level 2 represents the PERSON level: every student is characterised by individual baseline cortisol concentration and academic self-concept. We additionally consider person-related control variables. 
c) With regard to cross-classification, an additional Level 2 represents the level of CLASSROOM CONTEXT units where every 10-minute interval represents a "microsegment": every single segment of the classroom context is characterised by its individual degree of classroom demands. Within each single segment, the state measures of all persons present at the same place at a fixed point in time are nested.

d) Person-situation interactions are modelled via product terms of academic self-concept and classroom demands and of baseline cortisol concentration and classroom demands (cf. Baron \& Kenny, 1986; Hayes \& Matthes, 2009).

e) At Level 1, within-person differences are modelled by time-varying states (students' stress experience, situational coping, LF/HF ratio).

It is assumed that students' stress experience is nested as the dependent variable within PERSONS and within every single observation unit of the CLASSROOM CONTEXT at Level 2. Figure 2 illustrates the cross-classified data structure.

To reflect the cross-classified structure in the unobserved model component, we calculated two separate models, comparing them afterwards. Model \#1 considers random effects for intercept variance for the PERSON level and for the CLASSROOM CONTEXT level, changing at each interval of measurement. This allows for an estimation of the proportions of variance for the two nesting levels. Model \#1 also considers random effects for slope variance, and we assume that slopes vary randomly across classroom context segments, depending on academic self-concept and on baseline cortisol concentration. As an alternative, model \#2 focuses on the time dependence of measurements and considers an autoregressive covariance structure that "indicates that each person's distance measurement at one time is correlated with their distance measurement at the previous time period" (Leech et al., 2008, p. 201). Therefore, we modelled a first-order autoregressive covariance structure with homogenous variances (cf. Hox, 2002; Littell, Pendergast, \& Natarajan, 2000; Peugh \& Enders, 2005; Raudenbush \& Bryk, 2002; Twisk, 2006).

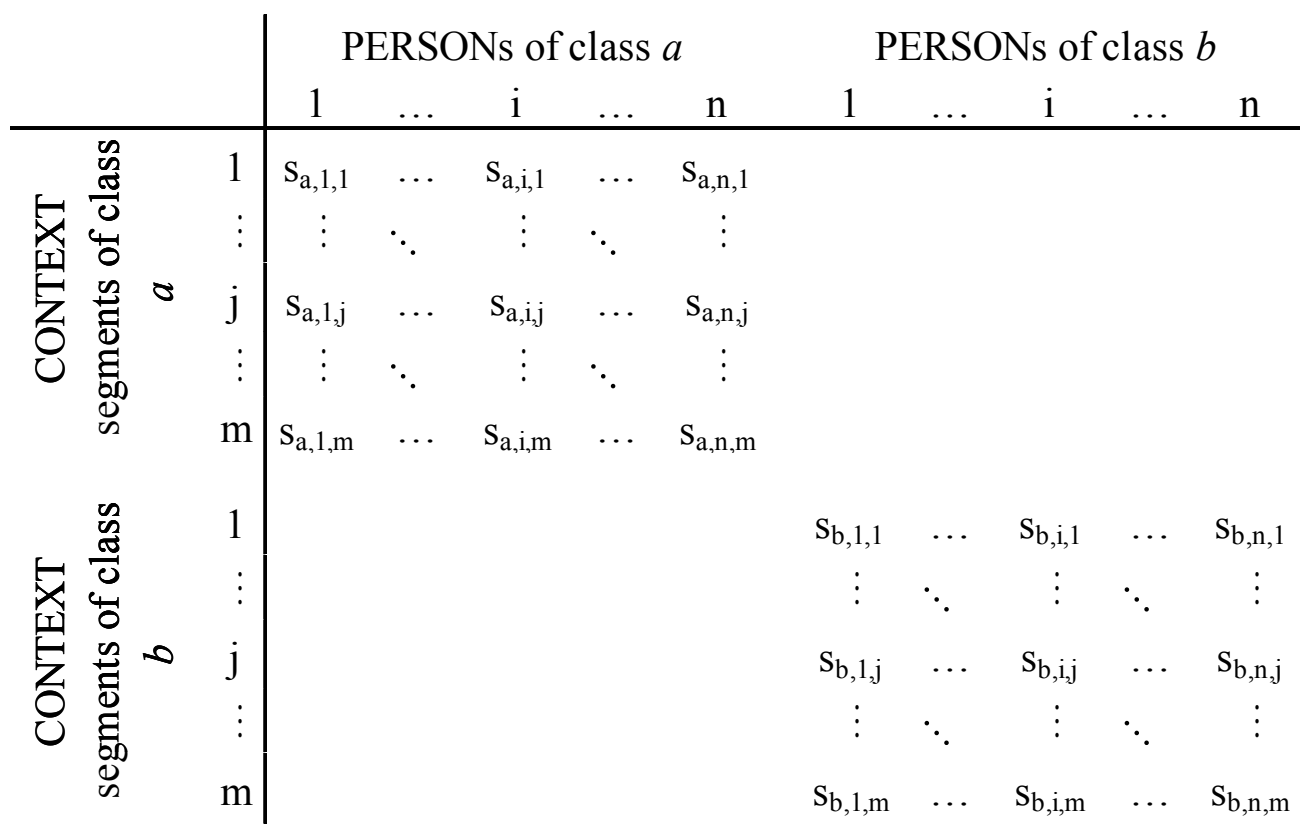

Figure 2. Cross-classified data structure with states nested within persons and within context segments 
The restricted maximum likelihood method was chosen as an estimation method, as it is adequate for small data sets (Heck et al., 2010). The analysis was realised using the SPSS ${ }^{\circledR}$ Mixed Procedure $^{\mathrm{TM}}$ (SPSS, 2005), an adequate tool for assessing cross-classified multilevel longitudinal modelling (Heck et al., 2010). Predictor variables and covariates were standardised. The statistical analyses were performed using SPSS $23{ }^{\circledR}\left(\right.$ IBM ${ }^{\circledR}$, Chicago, USA).

\subsubsection{Handling of missing values}

Note that missing values have been taken into account within the statistical analysis via multiple imputation (cf. Rubin, 1987; Raessler, Rubin \& Schenker, 2008). Using the multiple imputation routine implemented in SPSS, five imputed data sets have been analysed where the corresponding estimates have been joined using the classical combining rules established by Rubin (1987) and Little and Rubin (2002).

\section{Results}

\subsection{Previous analysis}

Table 1 shows the Pearson product-moment correlations among the variables. The correlations show that students' stress experience is significantly positive associated with age, AUCg, classroom demands at Level 2 (as single segments), and classroom demands at Level 3 (as class-related means). Further, SSE is significantly negative associated with academic self-concept and situational coping. SSE is not significantly associated with sex and LF/HF ratio, therefore these variables will not be considered as predictors in the multilevel analysis.

Table 1

Pearson product-moment correlations

\begin{tabular}{llllllll}
$(1)$ & $(2)$ & $(3)$ & $(4)$ & $(5)$ & $(6)$ & $(7)$ & $(8)$ \\
\hline
\end{tabular}

(1) Sex

(2) Age

(3) A. self-concept

(4) AUCg

$-.16^{* * *}$

(5) $\mathrm{LF} / \mathrm{HF}$ ratio

$-.35^{* * *}-.20^{* * *}$

(6) Situational coping

$-.07^{* *}-.12^{* * *}-.07^{* *}$

$-.22^{* * *} \quad .24^{* * *} \quad .00 \quad-.03$

$-.16^{* * *}-.03 \quad .47^{* * *}-.01$

.00

(7) $\begin{aligned} & \text { Class. demands } \\ & \text { (single segments) }\end{aligned}$

$-.07^{* *}-.05^{*} \quad-.13^{* * *} \quad .27^{* * *}-.12^{* * *}-.07^{* *}$

(8) Class. demands

(class mean)

$-.12^{* * *}-.08^{* * *}-.24^{* * *}$

$.50^{* * *}-.07-.12^{* * *}$

$.55^{* * *}$

(9) Students' stress

$.02 .19^{* * *}-.35^{* * *} .33^{* * *}$

.02

$-.41^{* * *}$

$.40^{* * *} .31^{* * *}$

Notes. ${ }^{* * *} p<.001,{ }^{* *} p<.01,{ }^{*} p<.05$; Sex: $0=$ male, $1=$ female 


\subsection{Multilevel analysis}

\subsubsection{Null models}

We primarily examined the single contributions to the explained variance of the different levels of model \#1. Therefore, we analysed the null model with SSE measures nested within students and within context segments (each at Level 2) and within classes (as Level 3 units) to check possible nesting-effects of the class affiliation. We found significant variances between persons and between context segments, but not between classes. Thus, the nesting-levels are the person-level and the context segment-level (cf. cross-classification) and not the class-level. But because of the significant class difference in general levels of classroom demands, we modelled the class-related means of classroom demands as a fixed effect at Level 3. The analysis of the null model with SSE measures nested within students and within context segments shows a significant between-students intercept variance of $.412(S E=.086, p<.001)$ and a significant between-context segment intercept variance of $.152(S E=.028, p<.001)($ see Table 2$)$.

The null model of model \#2 revealed a rho correlation of .721 $(S E=.015, p<.001)$ (see Table 2 ), that indicates a remarkable correlation between any two successive measurement points (cf. Heck et al., 2010).

\subsubsection{Mixed-effects model (model \#1) and fixed-effects model with AR1 (model \#2)}

Table 3 provides the results of the analysis of both multilevel models. The main effect of the class-related means of classroom demands (Level 3) remains non-significant in both analysed models. The main effect of the academic self-concept on students' stress experience remains negative and significant in model \#2 but not in model \#1. Baseline cortisol concentration has significant positive effects on SSE in both models. Limitations in the interpretability of the main effects will be mentioned below. Age as a control variable does affect SSE significantly positively in both models. The degree of classroom demands (Level 2) affects SSE positively and significantly in both models. At Level 1, situational coping has significantly negative effects on stress experience in both models.

Beside the found main effects on students' stress experience, we found significant interaction effects that can be interpreted as moderator effects (cf. Baron \& Kenny, 1986; Hayes \& Matthes, 2009): academic self-concept and baseline cortisol concentration affect the relation between classroom demands and students' stress experience. To illustrate the mentioned relations, the students were classified into three percentiles by their academic self-concept values as well as by their AUCg values. Concerning academic self-concept ( $s e l f c$ ) Group $a_{\text {selfc }}$ has a self-concept group-mean value of $M=3.19$ $(S D=.49)$, group $b_{\text {selfc }}$ has a mean value of $M=4.24(S D=.18)$, and the self-concept mean value of group $c_{\text {selfc }}$ is $4.90(S D=.29)$. The three groups differ significantly in their academic self-concept $(p<$ .001 , partial $\left.\eta^{2}=.798\right)$. Concerning AUCg Group $a_{A U C g}$ has a group-mean value of $M=2.93(S D=$ $1.55)$, group $b_{A U C g}$ has a mean value of $M=8.61(S D=2.32)$, and the AUCg mean value of group $c_{A U C g}$ is $19.97(S D=6.21)$. The three groups differ significantly in their areas under the curve values $(p$ $<.001$, partial $\eta^{2}=.767$ ). Figure 3a illustrates the group-specific linear growth trajectories of the three self-concept groups, and Figure $3 \mathrm{~b}$ illustrates the group-specific linear growth trajectories of the three AUCg groups: students who have low academic self-concept values show a stronger increase in stress experience with increasing classroom demands than students who have high self-concept values. On the other hand, students with high AUCg values show a stronger increase in stress experience with increasing classroom demands than students who have low AUCg values.

To check the characteristics of main effects and interaction effects, we referred to the classification of interaction effects of Leigh and Kinnear (1980) (see also Bortz \& Schuster, 2010). For both interaction effects (Figure 3a, Figure 3b) we found pure disordinal interactions (cf. crossed lines). This describes non-monotonic relations: the rank order of levels of one moderator factor (academic self-concept, $\mathrm{AUCg}$ ) does not remain constant over all levels of the abscissa factor (classroom 
demands); and the rank order of levels of the factor "classroom demands" does not remain constant over all levels of the factors "academic self-concept" and "AUCg". Therefore, the main effects of academic self-concept, AUCg, and classroom demands cannot be sensibly interpreted.

Table 3 also provides the variances of the random effects for model \#1 and of the repeated measures effect for model \#2. With regard to the random effects of model \# 1 we found a significant random intercept between-students variance of .139 (compared to the null model's random intercept variance between students of .412) and a significant random intercept variance between context segments of .045 (compared to the null model's random intercept variance between context segments of .152). The variance components suggest that the SSE slopes vary randomly across context segments in relation to baseline cortisol concentration, while showing no significant variance in relation to academic self-concept. With regard to the repeated measures in model \#2, Table 3 suggests a rho correlation of .565 (compared to the null model's rho correlation of .721). 
Table 2

Null models

\begin{tabular}{|c|c|c|c|c|c|c|c|c|c|c|}
\hline \multirow[b]{3}{*}{ Effect } & \multicolumn{5}{|c|}{$\begin{array}{c}\text { Model \#1 } \\
\text { Mixed-effects model }\end{array}$} & \multicolumn{5}{|c|}{$\begin{array}{l}\text { Model \#2 } \\
\text { Autoregressive covariance }\end{array}$} \\
\hline & \multirow[b]{2}{*}{ Estimate } & \multirow[b]{2}{*}{$S E$} & \multirow[b]{2}{*}{$p$} & \multicolumn{2}{|c|}{$95 \% C I$} & \multirow[b]{2}{*}{ Estimate } & \multirow[b]{2}{*}{$S E$} & \multirow[b]{2}{*}{$p$} & \multicolumn{2}{|c|}{$95 \% C I$} \\
\hline & & & & $L B$ & $U B$ & & & & $L B$ & $U B$ \\
\hline \multicolumn{11}{|l|}{ FIXED EFFECTS } \\
\hline Intercept & .003 & .100 & .972 & -.192 & 199 & -.023 & .052 & 657 & -.124 & .078 \\
\hline \multicolumn{11}{|l|}{ RANDOM EFFECTS } \\
\hline Residual variance & .427 & .015 & $<.001$ & .398 & .456 & & & & & \\
\hline Random intercept variance (Persons) & .412 & .086 & $<.001$ & .244 & .580 & & & & & \\
\hline Random intercept variance (Context segments) & .152 & .028 & $<.001$ & .096 & .208 & & & & & \\
\hline \multicolumn{11}{|l|}{ REPEATED MEASURES } \\
\hline AR1 diagonal & & & & & & .983 & .053 & $<.001$ & .879 & 1.087 \\
\hline AR $1 \rho$ & & & & & & .721 & .015 & $<.001$ & .691 & .751 \\
\hline
\end{tabular}


Table 3

Mixed-effects model and fixed-effects model (AR1)

\begin{tabular}{|c|c|c|c|c|c|c|c|c|c|c|}
\hline \multirow[b]{3}{*}{ Effect } & \multicolumn{5}{|c|}{$\begin{array}{c}\text { Model \#1 } \\
\text { Mixed-effects model }\end{array}$} & \multicolumn{5}{|c|}{$\begin{array}{c}\text { Model \#2 } \\
\text { Fixed-effects model (AR1) }\end{array}$} \\
\hline & \multirow[b]{2}{*}{ Estimate } & \multirow[b]{2}{*}{$S E$} & \multirow[b]{2}{*}{$p$} & \multicolumn{2}{|c|}{$95 \% C I$} & \multirow[b]{2}{*}{ Estimate } & \multirow[b]{2}{*}{$S E$} & \multirow[b]{2}{*}{$p$} & \multicolumn{2}{|c|}{$95 \% C I$} \\
\hline & & & & $L B$ & $U B$ & & & & $L B$ & $U B$ \\
\hline \multicolumn{11}{|l|}{ FIXED EFFECTS } \\
\hline Intercept & -.047 & .059 & .421 & -.163 & .068 & -.039 & .031 & .209 & -.100 & .022 \\
\hline \multicolumn{11}{|l|}{ LEVEL 3: CLASS } \\
\hline Classroom demands (class mean) & -.015 & .071 & .837 & -.153 & .124 & .034 & .039 & .384 & -.043 & .111 \\
\hline \multicolumn{11}{|l|}{ LEVEL 2: PERSON } \\
\hline Age & .228 & .055 & $<.001$ & .120 & .335 & .216 & .032 & $<.001$ & .153 & .279 \\
\hline Academic self-concept & -.108 & .057 & .060 & -.220 & .004 & -.105 & .034 & .002 & -.172 & -.038 \\
\hline $\mathrm{AUCg}$ & .238 & .063 & $<.001$ & .115 & .362 & .247 & .036 & $<.001$ & .177 & .318 \\
\hline \multicolumn{11}{|l|}{ LEVEL 2: CLASSROOM CONTEXT } \\
\hline Classroom demands (single segments) & .279 & .034 & $<.001$ & .212 & .346 & .172 & .022 & $<.001$ & .128 & .216 \\
\hline \multicolumn{11}{|l|}{ LEVEL 2: INTERACTIONS } \\
\hline Academic self-concept $\times$ Classroom demands & -.086 & .018 & $<.001$ & -.121 & -.051 & -.060 & .021 & .004 & -.101 & -.019 \\
\hline AUCg $\times$ Classroom demands & .127 & .021 & $<.001$ & .087 & .167 & .110 & .019 & $<.001$ & .072 & .148 \\
\hline \multicolumn{11}{|l|}{ LEVEL 1} \\
\hline Situational coping & -.283 & .022 & $<.001$ & -.326 & -.239 & -.297 & .024 & $<.001$ & -.344 & -.250 \\
\hline \multicolumn{11}{|l|}{ RANDOM EFFECTS } \\
\hline Residual variance & .370 & .013 & $<.001$ & .344 & .397 & & & & & \\
\hline Random intercept variance (Persons) & .139 & .031 & $<.001$ & .078 & .199 & & & & & \\
\hline Random intercept variance (Context segments) & .045 & .010 & $<.001$ & .024 & .065 & & & & & \\
\hline Random slope variance (Academic self-concept) & .001 & .003 & .675 & .000 & .006 & & & & & \\
\hline Random slope variance (AUCg) & .009 & .004 & .018 & .002 & .017 & & & & & \\
\hline \multicolumn{11}{|l|}{ REPEATED MEASURES } \\
\hline AR1 diagonal & & & & & & .562 & .025 & $<.001$ & .513 & .611 \\
\hline AR1 $\rho$ & & & & & & .565 & .019 & $<.001$ & .527 & .603 \\
\hline
\end{tabular}




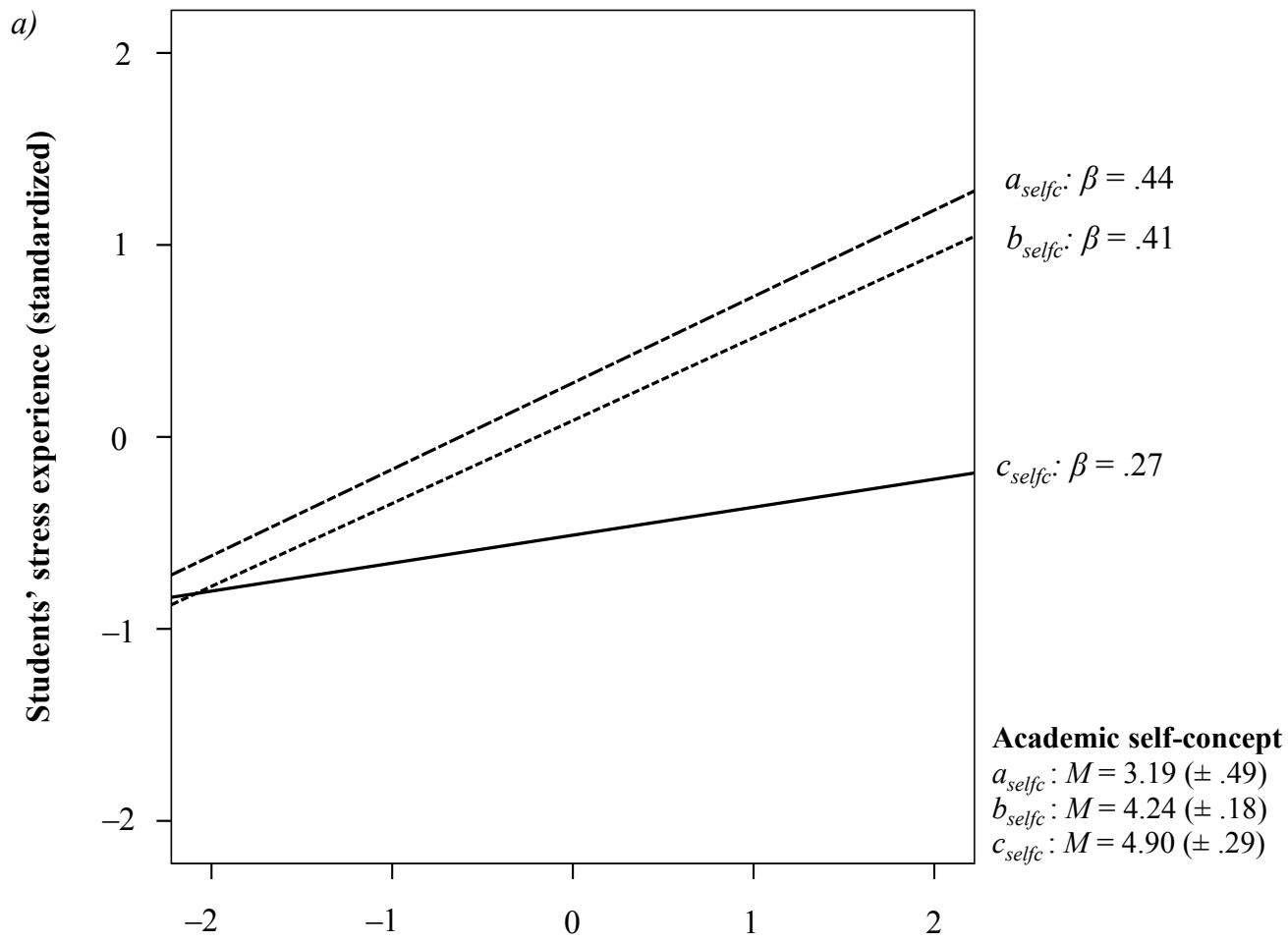

Classroom demands (standardized)

Figure 3a. Interaction: Academic self-concept $\times$ Classroom demands

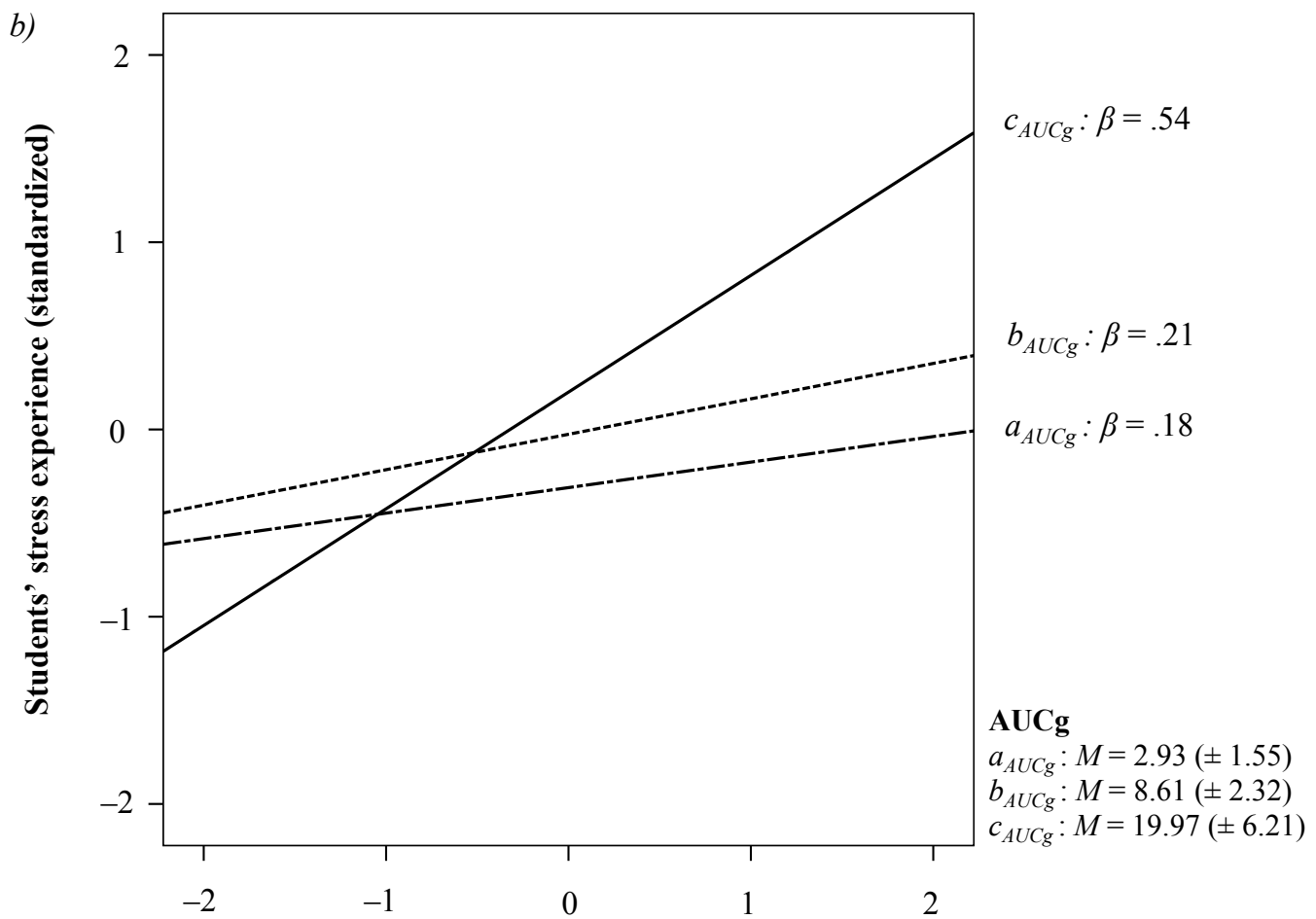

Classroom demands (standardized)

Figure $3 b$. Interaction: $\mathrm{AUCg} \times$ Classroom demands 


\subsubsection{Model comparisons}

To summarize the evidence referring to the different information and model selection criteria available for each imputed data set, we provide the median, minimum and maximum values for each information and model selection criterion. An inspection of the minimum and maximum values for the different criteria indicates that the autoregressive covariance structure is the overall preferred model specification (see Table 4 and Table 5).

Table 4

Model comparisons: Null models

\begin{tabular}{|c|c|c|c|c|c|c|}
\hline \multirow[t]{2}{*}{ Information criteria } & \multicolumn{3}{|c|}{$\begin{array}{c}\text { Model \#1 } \\
\text { Mixed-effects model }\end{array}$} & \multicolumn{3}{|c|}{$\begin{array}{c}\text { Model } \# 2 \\
\text { Autoregressive covariance }\end{array}$} \\
\hline & Median & Min. & Max. & Median & Min. & Max. \\
\hline Restricted -2 Log Likelihood & $4,372.6$ & $4,333.7$ & $4,394.1$ & $4,248.1$ & $4,227.5$ & $4,268.4$ \\
\hline Akaike Information Criterion (AIC) & $4,378.6$ & $4,339.7$ & $4,400.1$ & $4,252.1$ & $4,231.5$ & $4,272.4$ \\
\hline Hurvich and Tsai's Criterion (IC) & $4,378.6$ & $4,339.7$ & $4,400.1$ & $4,252.1$ & $4,231.5$ & $4,272.4$ \\
\hline Bozdogan Criterion (CAIC) & $4,398.4$ & $4,359.6$ & $4,420.0$ & $4,265.3$ & $4,244.8$ & $4,285.6$ \\
\hline Schwarz Criterion (BIC) & $4,395.4$ & $4,356.6$ & $4,417.0$ & $4,263.3$ & $4,242.8$ & $4,283.6$ \\
\hline
\end{tabular}

Table 5

Model comparisons: Mixed-effects model and fixed-effects model (AR1)

\begin{tabular}{|c|c|c|c|c|c|c|}
\hline \multirow[t]{2}{*}{ Information criteria } & \multicolumn{3}{|c|}{$\begin{array}{c}\text { Model \#1 } \\
\text { Mixed-effects model }\end{array}$} & \multicolumn{3}{|c|}{$\begin{array}{c}\text { Model \#2 } \\
\text { Autoregressive covariance }\end{array}$} \\
\hline & Median & Min. & Max. & Median & Min. & Max. \\
\hline Restricted -2 Log Likelihood & $4,042.3$ & $3,988.6$ & $4,053.1$ & $3,845.8$ & $3,826.9$ & $3,848.7$ \\
\hline Akaike Information Criterion (AIC) & $4,052.3$ & $3,998.6$ & $4,063.1$ & $3,849.8$ & $3,830.9$ & $3,852.7$ \\
\hline Hurvich and Tsai's Criterion (IC) & $4,052.4$ & $3,998.6$ & $4,063.1$ & $3,849.8$ & $3,830.9$ & $3,852.7$ \\
\hline Bozdogan Criterion (CAIC) & $4,085.4$ & $4,031.6$ & $4,096.1$ & $3,863.0$ & $3,844.1$ & $3,865.9$ \\
\hline Schwarz Criterion (BIC) & $4,080.4$ & $4,026.6$ & $4,091.1$ & $3,861.0$ & $3,842.1$ & $3,863.9$ \\
\hline
\end{tabular}

\section{Summary of results and discussion}

In our study, we investigated 53 students at a German vocational training school over a course of 9 lessons, examining students' stress response, considering psychological, physiological, and observational data. Via the continuous-state-sampling method we assessed almost 38 state measurements per person, adding up to a cumulative total of 2,014 measurements. To analyse effects on students' stress experience, a cross-classified multilevel analysis was applied.

We hypothesised that the baseline cortisol concentration should have been positively associated with students' stress experience. The analysis shows a main effect of baseline cortisol 
concentration (operationalised by an individual's area under the curve with respect to the ground) on SSE (sees Table 3). This main effect is consistent with existing research, because cortisol concentration during the day is an endocrinological indicator for chronic stress that may suggest a chronic elevation of HPA activation (Wüst et al., 2000; Takahashi et al., 2005). However, the found main effect cannot be reasonably interpreted due to the found pure disordinal interaction between AUCg and classroom demands (cf. Leigh \& Kinnear, 1980).

Contrary to our hypothesis, the LF/HF ratio as a time-varying somatic stress indicator is not significantly associated with SSE (see Table 1). This finding is not consistent with the existing literature that indicates that there should be a predominant status of the sympathetic nervous system that is activated under stress, accompanied by an underrepresented status of the parasympathetic nervous system that controls physiological resting functions (cf. Kemeny, 2003; Hjortskov et al., 2004; Isowa et al., 2006). From a conceptual point of view, the non-significant correlation between $\mathrm{SSE}$ and LF/HF ratio could result from the general stress level in class. In reference to the rating scale from 0 (= "I fully disagree") to 100 (= "I fully agree") we found mean values lower than average for perceived time pressure $(M=17.44, S D=25.01)$ and pressure to succeed $(M=20.62, S D=25.43)$. However, existing studies show a synchrony of different stress systems only in highly stressful situations (Looser et al., 2010). From a methodological point of view, correlations between self-ratings and physiological measures are assumed to be quite lower than correlations between different selfrating variables (cf. Campbell \& Fiske, 1959).

We hypothesised that academic self-concept should be negatively associated with students' stress experience. The Pearson product-moment correlations show a significant and negative correlation $(r=-.35$, see Table 1$)$ with the multilevel model \#2 also revealing a significant negative effect. The main effect of academic self-concept on stress experience remains negative but nonsignificant in model \#1. However, the main effect of the self-concept cannot be sensibly interpreted due to the found pure disordinal interaction between self-concept and classroom demands.

With regard to the situational coping that was operationalised by the items "I can cope with actual demands" and "I understand subject matter", we found a significant and positive effect on stress experience conforming to our hypothesis. However, in that regard we have to consider potential effects of common method biases. The items related to both variables (students' stress experience, situational coping) were measured by continuous-state-sampling method. With respect to Podsakoff et al. (2003) one has to consider possible method effects produced by item characteristics, as the way in which the items are presented to the students (scale format, scale anchors) was the same for the used state-items. Further, one has to take into account possible method effects produced by the measurement context. State-items of both variables have been measured concurrently with regard to time and location of measurement, using the same medium for measurement as well. Therefore, it seems to be worthwhile in future research to operationalise situational coping via observational methods instead of through self-rating items (cf. Roubinov, Hagan, \& Luecken, 2012; Wuttke, 2000).

As hypothesised, we found a main effect of classroom demands (Level 2) on students' stress experience. However, the found main effect cannot be sensibly interpreted because of the found pure disordinal interactions (cf. Leigh \& Kinnear, 1980). The main effect of classroom demands (Level 3) on SSE remains non-significant.

Besides the previously discussed main effects on students' stress experience, a significant person-situation interaction occurs between academic self-concept and the degree of classroom demands: students who have low academic self-concept values show a stronger increase in stress experience with increasing classroom demands than students who have high self-concept values (see Figure 3a). This finding is in line with our hypothesis. The "objective" degree of classroom demands is perceived as stressful in different ways depending on a subjective appraisal of potential coping resources. Following Lazarus and colleagues, a stressor is first interpreted with regard to its perceived relevance (indeed, it is a basic assumption of the current study that the students interpret the lessons as being relevant to them). If it is interpreted as relevant and threatening, the secondary appraisal entails 
an analysis of available resources and self-confidence in order to cope with the situation appropriately (cf. Lazarus, 1984; Lazarus \& Folkman, 1984).

In addition to the interaction between self-concept and classroom demands, the assumed person-situation interaction between baseline cortisol concentration and classroom demands also remains significant: students with high AUCg values show a stronger increase in stress experience with increasing classroom demands than students who have low AUCg values (see Figure 3b). With reference to the literature, high baseline cortisol values are associated with a chronic elevation in the level of HPA activation (cf. Wüst et al., 2000; Takahashi et al., 2005). In regard to the diathesis-stress model, physiological vulnerability - such as a chronic elevation of baseline cortisol concentration - in turn affects the relation between stressful context conditions and stress experience as a possible stress response. In other words: the higher the vulnerability, the greater the responsiveness to demanding conditions (cf. Belsky \& Pluess, 2009).

Our findings on person-situation interactions indicate that "objective" conditions in class may be experienced very differently depending on individual characteristics. Or with the words of Krohne (1990, p. 27): "[the] process of cognitively transforming objective characteristics into subjective representations is clearly codetermined by personality dispositions." Furthermore, it seems to be important to take into greater consideration possible interaction effects between person- and situationrelated variables in learning research. Otherwise, there is the risk of overestimating main effects of person- and situation-related variables.

So far, our findings draw quite a negative picture of class-related demands. However, one has to consider that challenges can also encourage an individual's development. For example, experiencing mastery over a demanding situation powerfully impacts an individual's self-efficacy beliefs (Bandura, 1977). Further, the concept of the "zone of proximal development" suggests the importance of overcoming barriers for an individual's competency development within a social context (Vygotskii, 1978). Nonetheless, it remains a pivotal endeavour for teachers and learning researchers to design and implement teaching and learning arrangements where learners can gain such experiences of mastery within a protected and supportive environment (cf. Sembill, 1999).

\section{Limitations of the study}

The design of our study has advantages as well as limitations. The naturalistic setting and the high frequency of data sampling offer a high degree of ecological validity (cf. Sembill, Seifried, \& Dreyer, 2008) further ensured by the situational specificity of data sampling (Hormuth, 1986; Wild, 2001). On the other hand, the naturalistic setting bears the risk of confounding variables that may bias the results. Therefore, for further research a combination of naturalistic settings and laboratory experimental conditions seems to be worthwhile. For example, specific class-related stressors could be identified in naturalistic learning contexts, to be validated within later laboratory experiments.

Another potential limitation of our study appears in regard to the collection of saliva samples as the basis for measurement of cortisol concentrations. Indeed, all participants were instructed to adhere strictly to the prescribed sampling times, but sampling times could not be strictly monitored. Further research would necessitate employing methods of electronic medication event monitoring (e.g. Medication Event Monitoring Systems [MEMS ${ }^{\circledR}$ ], Aardex Ltd., Schweiz; see also Rösler et al., 2010; Kudielka, Borderick, \& Kirschbaum, 2003).

Furthermore, our analysis only focuses on a relatively narrow scope within the discussion of stress among students. We considered only students' academic self-concept; the baseline cortisol concentration; the LF/HF ratio, as an indicator for heart rate variability; and as indicators for classroom demands, the amount of student-centred learning and the levels of cognitive challenge 
during education. Taking account for the wide range of other stress- and coping-related variables, further research should also focus on other relevant traits (e.g. emotion-focused and problem-focused strategies, behavioural inhibition and behavioural activation), on additional situational characteristics (such as variations in domain-specific learning contents or didactic methods), and on other dependent variables in terms of psychological, physiological, and behavioural states.

\section{Conclusions and implications for future research}

In conclusion, a deeper knowledge about the complex interrelations between traits, states, and continuous changing context conditions seems to be essential for a more holistic understanding of learning at school and for the identification of crucial aspects for an evidence-based design and implementation of teaching and learning arrangements that are able to meet individual's requirements in an optimal way. Thus, further learning process research should focus more intensively on causal relationships and regulatory feedback mechanisms between (1) psychological and physiological characteristics; (2) situational context conditions during education; (3) psychological, physiological, and behavioural states; and (4) learning outcomes such as domain-specific competencies.

From a methodological point of view, there are some implications for further research on such complex interrelations. Our analysis only took account for unidirectional relations (personal and situational variables $\rightarrow$ states). However, in line with the transactional model of stress and coping (Lazarus, 1984; Lazarus \& Folkman, 1984) one must assume reciprocal relations: expressed emotions and behaviours, in turn constituting new and modified situations and context conditions. Furthermore, we only took linear relationships into account. However, particularly in stress research, empirical evidence shows non-linear relations between demanding conditions and neurophysiological processes that are described by inverted U-shaped curves (e.g. Diamond et al., 1992; Hebb, 1955; Yerkes \& Dodson, 1908). Another aspect worth considering in future research is that possible interaction effects between personal characteristics and situational conditions during class themselves may be affected by variables - such as school climate or aspects of class composition - that are located on higher levels and that account for variations in the nature of interaction effects on lower levels. But in that case, a thorough examination of possible context effects on the basis of aggregated context data seems worthwhile. However, the consideration of characteristics of "micro-segments" of the classroom context that are constituted by process-related characteristics might be more precise than an exclusive consideration of possible effects of aggregated data (e.g. class-related means for classroom demands).

With regard to high frequency assessments of classroom conditions, future research should focus on a "multidimensional mapping" of context conditions and on an analysis of corresponding effects on students' learning, experience, and achievement. In the current analysis, we only considered classroom demands as one possible dimension of the context. But one can imagine considering multiple dimensions in the same way, for instance looking at learning objectives, learning contents, didactic methods, and media as core dimensions of the Berlin model of didactics (summarizing Klafki, 1995 and Zierer \& Seel, 2012) or considering classroom organisation, student orientation, and cognitive activation as dimensions of instructional quality (Wagner et al., 2013). Such research could finally result in empirically validated "multidimensional cubes" that characterise the antecedents and effects of successful classroom learning.

From a conceptual point of view, it will be a challenge for future applied learning process research to translate its empirical and theoretical findings into appropriate recommendations for classroom practitioners leading to an evidence-based design and implementation of teaching and learning arrangements. 


\section{Keypoints}

- Academic self-concept and baseline cortisol concentration affect the relationship between classroom demands and students' stress experience.

- Cross-classified multilevel longitudinal modelling is a capable method for investigating associations between traits, states, and "objective" situational context conditions in naturalistic learning processes.

- It seems to be important to take into greater consideration possible interaction effects between person- and situation-related variables in learning research. Otherwise, there is a risk of overestimating corresponding main effects of person- and situation-related variables.

- A deeper knowledge about the complex interrelations between traits, states, and continuous changing context conditions seems to be essential for a more holistic understanding of learning at school and for the identification of crucial aspects for an evidence-based design and implementation of teaching and learning arrangements.

\section{Abbreviations}

ATI: aptitude treatment interaction; AUCg: area under the curve with respect to the ground; HF: high frequency (domain); HPA axis: hypothalamic-pituitary-adrenal axis; Hz: Hertz; LF: low frequency (domain); SC: situational coping; SSE: students' stress experience

\section{Acknowledgments}

The authors would like to thank the anonymous reviewers for their critical, but very helpful and constructive comments and suggestions, especially with regard to the statistical analysis and to the line of argument. Further, the authors would like to thank Douglas Boatwright (Berlin, Germany) for the professional proof-reading of our manuscript.

\section{References}

Achtenhagen, F. (1978). Beanspruchung von Schülern. Methodisch-didaktische Aspekte [Students' stress. Methodical and didactical aspects]. BMBW Werkstattberichte, Bundesminister für Bildung und Wissenschaft. Regensburg: Aumüller Druck KG.

Adam, E. K. (2006). Transactions among adolescent trait and state emotion and diurnal and momentary cortisol activity in naturalistic settings. Psychoneuroendocrinology, 31 (5), 664-679. doi: 10.1016/j.psyneuen.2006.01.010

Agelink, M. W., Malessa, R., Baumann, B., Majewski, T., Akila, F., Zeit, T., \& Ziegler D. (2001). Standardized tests of heart rate variability: normal ranges obtained from 309 healthy humans, and effects of age, gender, and heart rate. Clinical Autonomic Research, 11 (2), 99-108. doi: 10.1007/BF02322053

Baert, S., Casier, A., \& De Raedt, R. (2012). The effects of attentional training on physiological stress recovery after induced social threat. Anxiety, Stress, \& Coping: An International Journal, 25 (4), 365-379. doi: 10.1080/10615806.2011.605122

Bandura, A. (1977). Self-efficacy: Toward a Unifying Theory of Behavioral Change. Psychological Review, 84 (2), 191-215. doi: 10.1037/0033-295X.84.2.191 
Baron, R. M. \& Kenny, D. A. (1986). The Moderator-Mediator Variable Distinction in Social Psychological Research: Conceptual, Strategic, and Statistical Considerations. Journal of Personality and Social Psychology, 51 (6), 1173-1182. doi: 10.1037/0022-3514.51.6.1173

Beck, K. \& Sczesny, C. (1993). Zur Psychophysiologie des Lernens in der Computerinteraktion. Grundprobleme, Forschungsresultate, Untersuchungsperspektiven. Bericht zum Forschungsprojekt „Prozeßanalyse computergestützen Lernens“ [To the psychophysiology of learning within human-computer interaction. Basic problems, research findings, perspectives of investigation. Report to the research project "Process-analysis of computer-assisted learning"]. Nürnberg: University Erlangen-Nürnberg.

Belsky, J. \& Pluess, M. (2009). Beyond diathesis stress: Differential susceptibility to environmental influences. Psychological Bulletin, 135 (6), 885-908. doi: 10.1037/a0017376

Bloom, B. S., Engelhart, M. D., Furst, E. J., Hill, W. H., \& Krathwohl, D. R. (1956). Taxonomy of educational objectives: The classification of educational goals. Handbook I: Cognitive domain. New York: David McKay Company.

Bong, M. \& Skaalvik, E. M. (2003). Academic Self-Concept and Self-Efficacy: How Different Are They Really? Educational Psychology Review, 15 (1), 1-40. doi: 10.1023/A:1021302408382

Bortz, J. \& Schuster, C. (2010). Statistik für Human- und Sozialwissenschaftler [Statistics for the humanities and social sciences]. Springer: Berlin.

Bryk, A. S. \& Raudenbush, S. W. (1992). Hierarchical Linear Models: Applications and Data Analysis Methods. London: Sage Publications.

Buchanan, T. W. \& Lovallo W. R. (2001). Enhanced memory for emotional material following stresslevel cortisol treatment in humans. Psychoneuroendocrinology, 26 (3), 307-317. doi: $10.1016 / \mathrm{S} 0306-4530(00) 00058-5$

Campbell, D. T. \& Fiske, D. W. (1959). Convergent and discriminant validation by the multitraitmultimethod matrix. Psychological Bulletin, 56 (2), 81-105, doi: 10.1037/h0046016

Caplan, R. D., Cobb, S., \& French, J. R. P. Jr. (1979). White collar work load and cortisol: Disruption of a circadian rhythm by job stress? Journal of Psychosomatic Research, 23 (3), 181-192. doi: 10.1016/0022-3999(79)90003-5

Carver, Ch. S. \& Scheier, M. F. (2008). Perspectives on Personality. Boston: Pearson.

Cobas (2010). Leistungsdaten von Elecsys ${ }^{\circledR}$ und cobas $e^{\circledR}$ Geräten hinsichtlich der Bestimmung des Cortisolwertes $\left[\right.$ Performance data for Elecsys ${ }^{\circledR}$ and cobas $e^{\circledR}$ equipment concerning the identification of salvia cortisol concentration]. (W. Mayer, Immumed GmbH, Karlstrasse 46, 80333 Munich, Germany). Technical manuscript.

Cronbach, L. J. \& Snow, R. E. (1977). Aptitudes and Instructional Methods. A Handbook for Research on Interactions. New York: Irvington Publishers.

Csíkszentmihályi, M. \& Larson, R. (1987). Validity and Reliability of the Experience-Sampling Method. The Journal of Nervous and Mental Diseases, 175 (9), 526-536. doi: 10.1097/00005053-198709000-00004

Danev, S. (2010). QHRV-Lite System Guide \& User's Manual. Medeia Ltd.

Deci, E. L. \& Ryan, R. M. (1985). Intrinsic Motivation and Self-Determination in Human Behavior. New York: Plenum Press.

Diamond, D. M., Bennett, M. C., Fleshner, M., \& Rose, G. M. (1992). Inverted-U Relationship between the Level of Peripheral Corticosterone and the Magnitude of Hippocampal Primed Burst Potention. Hippocampus, 2 (4), 421-430. doi: 10.1002/hipo.450020409

Dickerson, S. S. \& Kemeny, M. E. (2004). Acute Stressors and Cortisol Responses: A Theoretical Integration and Synthesis of Laboratory Research. Psychological Bulletin, 130 (3), 355-391. doi: 10.1037/0033-2909.130.3.355

Ellenbogen, M. A. (2012). Introduction to the special section on biopsychosocial moderators of the stress response. Anxiety, Stress, \& Coping: An International Journal, 25 (4), 359-364. doi: 10.1080/10615806.2012.691621

Fekedulegn, D. B., Andrew, M. E., Burchfiel, C. M., Violanti, J. M., Hartley, T. A., Charles, L. E., \& Miller, D. B. (2007). Area under the curve and other summary indicators of repeated waking 
cortisol measurements. Psychosomatic Medicine, 69 (7), 651-659. doi: 10.1097/PSY.0b013e31814c405c

Goetz, T., Preckel, F., Zeidner, M., \& Schleyer, E. (2008). Big fish in big ponds: A multilevel analysis of test anxiety and achievement in special gifted classes. Anxiety, Stress, \& Coping: An International Journal, 21 (2), 185-198. doi: 10.1080/10615800701628827

Goldstein, H. (1994). Multilevel Cross-Classified Models. Sociological Methods Research, 22 (3), 364-375. doi: 10.1177/0049124194022003005

Goldstein, H., Healy, M. J., \& Rasbash, J. (1994). Multilevel time series models with applications to repeated measures data. Statistics in Medicine, 13 (16), 1643-1655. doi: $10.1002 / \operatorname{sim} .4780131605$

Hall, J. E. (2011). Guyton and Hall Textbook of Medical Physiology. Philadelphia: Saunders Elisever.

Hayes, A. F. \& Matthes, J. (2009). Computational procedures for probing interactions in OLS and logistic regression: SPSS and SAS implementations. Behavior Research Methods, 41 (3), 924 936. doi: 10.3758/BRM.41.3.924

Hebb, D. O. (1955). Drives and the C.N.S (Conceptual Nervous System). The Psychological Review, 62 (4), 243-254. doi: 10.1037/h0041823

Heck, R. H. \& Thomas, S. L. (2009). An Introduction to Multilevel Modeling Techniques. New York: Routledge.

Heck, R. H., Thomas, S. L., \& Tabata, L. N. (2010). Multilevel and Longitudinal Modeling with IBM SPSS. New York: Routledge.

Hill, P. W. \& Goldstein, H. (1998). Multilevel Modeling of Educational Data with CrossClassification and Missing Identification for Units. Journal of Educational and Behavioral Statistics, 23 (2), 117-128. doi: 10.3102/10769986023002117

Hjortskov, N., Rissén, D., Blangsted, A. K., Fallentin, N., Lundberg, U., \& Søgaard, K. (2004). The effect of mental stress on heart rate variability and blood pressure during computer work. European Journal of Applied Physiology, 92 (1-2), 84-89. doi: 10.1007/s00421-004-1055-z

Hormuth, S. E. (1986). The sampling of experience in situ. Journal of Personality, 54 (1), 262-293. doi: 10.1111/j.1467-6494.1986.tb00395.x

Hox, J. (2002). Multilevel Analysis. Techniques and Applications. London: Lawrence Erlbaum Associates.

Isowa, T., Ohira, H., \& Murashima, S. (2006). Immune, endocrine and cardiovascular responses to controllable and uncontrollable acute stress. Biological Psychology, 71 (2), 202-213. doi: 10.1016/j.biopsycho.2005.04.002

Kärner, T. (2015). Erwartungswidrige Minderleistung und Belastung im kaufmännischen UnterrichtAnalyse pädagogischer, psychologischer und physiologischer Aspekte [Underachievement and stress in vocational business education - analysis of pedagogical, psychological, and physiological aspects]. Frankfurt a. M.: Lang.

Kemeny, M. E. (2003). The Psychobiology of Stress. Current Directions in Psychological Science, 12 (4), 124-129. doi: 10.1111/1467-8721.01246

Kendall, P. C. (1981). Anxiety: States, Traits-Situations? In A. Furnham \& M. Argyle (eds.), The Psychology of Social Situations: Selected Readings, (pp. 208-220). Oxford: Pergamon Press.

Klafki, W. (1995). Didactic analysis as the core of preparation of instruction. Journal of Curriculum Studies, 27 (1), 13-30. doi: 10.1080/002202795027010

Kouzma, N. M. \& Kennedy, G. A. (2004). Self-Reported Sources of Stress in Senior High School Students. Psychological Reports, 94 (1), 314-316. doi: 10.2466/pr0.94.1.314-316

Kristof-Brown, A. L., Zimmerman, R. D., \& Johnson, E. C. (2005). Consequences of individuals' fit at work: A meta-analysis of person-job, person-organization, person-group, and personsupervisor fit. Personnel Psychology, 58 (2), 281-342. doi: 10.1111/j.1744-6570.2005.00672.x

Krohne, H. W. (1990). Personality as a Mediator Between Objective Events and Their Subjective Representation. Psychological Inquiry, 1 (1), 26-29. doi: 10.1207/s15327965pli0101_7 
Kudielka, B., Borderick, J. E., \& Kirschbaum, C. (2003). Compliance with saliva sampling protocols: Electronic monitoring reveals invalid cortisol daytime profiles in noncompliant subjects. Psychosomatic Medicine, 65 (2), 313-319. doi: 10.1097/01.PSY.0000058374.50240.BF

Lazarus, R. S. (1966). Psychological Stress and Coping Process. New York: McGraw-Hill Book Company.

Lazarus, R. S. (1984). On the Primacy of Cognition. American Psychologist, 39 (2), 124-129. doi: 10.1037/0003-066X.39.2.124

Lazarus, R. S. (1999). Stress and Emotion. A New Synthesis. New York: Springer.

Lazarus, R. S. \& Folkman, S. (1984). Stress, Appraisal, and Coping. New York: Springer.

Leech, N. L., Barrett, K. C., \& Morgan, G. A. (2008). SPSS for Intermediate Statistics. Use and Interpretation. New York: Taylor \& Francis.

Leigh, J. H. \& Kinnear, T. C. (1980). On interaction classification. Educational and Psychological Measurement, 40 (4), 841-843. doi: 10.1177/001316448004000405

Littell, R. C., Pendergast, J., \& Natarajan, R. (2000). Tutorial in biostatistics: Modelling covariance structure in the analysis of repeated measures data. Statistics in Medicine, 19 (13), 1793-1819. doi: 10.1002/1097-0258(20000715)19:13<1793::AID-SIM482>3.0.CO;2-Q

Little, R. J. A. \& Rubin, D. B. (2002). Statistical Analysis with Missing Data. New Jersey: Wiley.

Looser, R. R., Metzenthin, P., Helfricht, S., Kudielka, B. M., Loerbroks, A., Thayer, J. F., \& Fischer, J. E. (2010). Cortisol Is Significantly Correlated With Cardiovascular Responses During High Levels of Stress in Critical Care Personnel. Psychosomatic Medicine, 72 (3), 281-289. doi: 10.1097/PSY.0b013e3181d35065

Luria, R. E. (1975). The validity and reliability of the visual analogue mood scale. Journal of Psychiatric Research, 12 (1), 51-57. doi: 10.1016/0022-3956(75)90020-5

Malik, M., Bigger, J. T., Camm, A. J., Kleiger, R. E., Malliani, A., Moss, A. J., \& Schwartz, P. J. [Task Force of The European Society of Cardiology and The North American Society of Pacing and Electrophysiology] (1996). Heart rate variability: Standards of measurement, physiological interpretation, and clinical use. European Heart Journal, 17 (3), 354-381.

Michaud, K., Matheson, K., Kelly, O., \& Anisman, H. (2008). Impact of Stressors in a natural context on release of cortisol in healthy adult humans: A meta-analysis. Stress, 11 (3), 177-197. doi: $10.1080 / 10253890701727874$

Nezlek, J. B. (2007). A Multilevel Framework for Understanding Relationships Among Traits, States, Situations and Behaviours. European Journal of Personality, 21 (6), 789-810. doi: $10.1002 /$ per. 640

Peugh, J. L. \& Enders, C. K. (2005). Using the SPSS Mixed Procedure to Fit Cross-Sectional and Longitudinal Multilevel Models. Educational and Psychological Measurement, 65 (5), 717-741. doi: $10.1177 / 0013164405278558$

Podsakoff, P. M., MacKenzie, S. B., Lee, J.-Y., \& Podsakoff, N. P. (2003). Common Method Biases in Behavioral Research: A Critical Review of the Literature and Recommended Remedies. Journal of Applied Psychology, 88 (5), 879-890. doi: 10.1037/0021-9010.88.5.879

Pruessner, J. C., Kirschbaum, C., Meinlschmid, G., \& Hellhammer, D. H. (2003). Two formulas for computation of the area under the curve represent measures of total hormone concentration versus time-dependent change. Psychoneuroendocrinology, 28 (7), 916-931. doi: 10.1016/S0306-4530(02)00108-7

Raessler, S., Rubin, D. B., \& Schenker, N. (2008). Incomplete Data: Diagnosis, Imputation, and Estimation. In E. D. de Leeuw, J. J. Hox, \& D. A. Dillman (eds.), International Handbook of Survey Methodology, (pp. 370-386). New York: Lawrence Erlbaum.

Raudenbush, S. W. \& Bryk, A. S. (2002). Hierarchical Linear Models. Applications and Data Analysis Methods, Second Edition. London: Sage.

Rieser, S., Fauth, B., Decristan, J., Klieme, E., \& Büttner, G. (2013). The connection between primary school students' self-regulation in learning and perceived teaching quality. Journal of Cognitive Education and Psychology, 12 (2), 138-156. doi:10.1891/1945-8959.12.2.138 
Rösler, U., Gebele, N., Hoffmann, K., Morling, K., Müller, A., Rau, R., \& Stephan, U. (2010). Cortisol - ein geeigneter physiologischer Indikator für Belastungen am Arbeitsplatz? [Cortisol a useful physiological parameter for work-related stress?] Zeitschrift für Arbeits- und Organisationspsychologie, 54 (2), 68-82. doi: 10.1026/0932-4089/a000011

Rost, D. H., Sparfeldt, J. R., \& Schilling, S. R. (2007). DISK-GITTER mit SKSLF-8. Differentielles Schulisches Selbstkonzept-Gitter mit Skala zur Erfassung des Selbstkonzepts schulischer Leistungen und Fähigkeiten [Scale for assessing Self-concept of School related Achievement and Skills]. Göttingen: Hogrefe.

Roubinov, D., Hagan M. J., \& Luecken L. J. (2012). If at first you don't succeed: the neuroendocrine impact of using a range of strategies during social conflict. Anxiety, Stress, \& Coping: An International Journal, 25 (4), 397-410. doi: 10.1080/10615806.2011.613459

Rubin, D. B. (1987). Multiple Imputation for Nonresponse in Surveys. Hoboken, NJ: Wiley-IEEE.

Saxbe, D. E. (2008). A field (researcher's) guide to cortisol: tracking HPA axis functioning in everyday life. Health Psychology Review, 2 (2), 163-190. doi: 10.1080/17437190802530812

Schunk, D. H. \& Zimmerman, B. J. (eds.) (1994). Self-Regulation of Learning and Performance. Issues and Edicational Applications. Hillsdale: Lawrence Erlbaum.

Scollon, Ch. N., Kim-Prieto, Ch., \& Diener, E. (2003). Experience Sampling: Promises and Pitfalls, Strengths and Weaknesses. Journal of Happiness Studies, 4 (1), 5-34. doi: 10.1023/A:1023605205115

Seidel, T., Dalehefte, I. M., \& Meyer, L. (2001). Videoanalysen - Beobachtungsschemata zur Erfassung von "Sicht-Strukturen“ im Physikunterricht [Video-based analysis - observation patterns for assessing conditions in classroom in physics education]. In M. Prenzel, R. Duit, M. Euler, M. Lehrke, \& T. Seidel (eds.), Erhebungs- und Auswertungsverfahren des DFG-Projekts „Lehr-Lern-Prozesse im Physikunterricht - eine Videostudie“, (pp. 41-58). Kiel: IPNMaterialien.

Seifried, J. (2004). Fachdidaktische Variationen in einer selbstorganisationsoffenen Lernumgebung. Eine empirische Untersuchung im Rechnungswesenunterricht [Subject-didactical variations in a self-organized learning environment. An empirical study in accounting education]. Wiesbaden: Deutscher Universitäts-Verlag.

Sembill, D. (1984). Modellgeleitete Interaktionsanalysen im Rahmen einer forschungsorientierten Lehrerausbildung - am Beispiel von Untersuchungen zum „Kaufvertrag" [Modell-driven interaction analysis within the scope of research oriented teacher education by the example of the topic "purchase agreement"]. Dissertation, Georg-August-Universität Göttingen, Germany.

Sembill, D. (1999). Selbstorganisation als Modellierungs-, Gestaltungs- und Erforschungsidee beruflichen Lernens [Self-organisation as idea for modelling, design, and research of vocational learning]. In T. Tramm, D. Sembill, F. Klauser, \& E. G. John (eds.), Professionalisierung kaufmännischer Berufsbildung. Festschrift zum 60. Geburtstag von Frank Achtenhagen [Professionalisation of commercial vocational education. Festschrift to the 60th birthday of Frank Achtenhagen], (pp. 146-174). Frankfurt a. M.: Peter Lang.

Sembill, D. (2004). Abschlussbericht an die Deutsche Forschungsgemeinschaft im Rahmen des Schwerpunktprogramms „Lehr-Lern-Prozesse in der kaufmännischen Erstausbildung “ [Final report to the German Research Foundation within the scope of the priority programme "Teaching and Learning Processes in Business Education"]. http://www.uni-bamberg.de/fileadmin/uni/fakultaeten/sowi_lehrstuehle/wirtschaftspaedagogik/Dateien/Forschung/Forschungsprojekte/Prozessanalysen/DFG-Abschlussbericht_sole.pdf. Accessed 10 July 2013.

Sembill, D., Rausch, A., \& Kögler, K. (2013). Non-cognitive facets of competence - Theoretical foundations and implications for measurement. In K. Beck \& O. Zlatkin-Troitschanskaia (eds.), From Diagnostics to Learning Success: Proceedings in Vocational Education and Training, (pp. 199-212). Rotterdam: Sense.

Sembill, D., Seifried, J., \& Dreyer, K. (2008). PDAs als Erhebungsinstrument in der beruflichen LehrLern-Forschung - Ein neues Wundermittel oder bewährter Standard? Eine Replik auf Henning 
Pätzold [PDAs as a tool for data collection in adult education research - New panacea or approved standard? A reply to Henning Pätzold]. Empirische Pädagogik, 22 (1), 64-77.

Sembill, D., Wolf, K. D., Wuttke, E., \& Schumacher, L. (2002). Self-Organized Learning in Vocational Education - Foundation, Implementation, and Evaluation. In K. Beck (ed.), TeachingLearning Processes in Vocational Education. Foundations of Modern Training Programms, (pp. 267-295). Frankfurt a.M.: Peter Lang.

Shavelson, R. J., Hubner, J. J., \& Stanton, G. C. (1976). Self-Concept: Validation of Construct Interpretations. Review of Educational Research, 46 (3), 407-441. doi: 10.1037/00223514.45.1.173

Shedletsky, R. \& Endler, N. S. (1974). Anxiety: The state-trait model and the interaction model. Journal of Personality, 42 (4), 511-527. doi: 10.1111/j.1467-6494.1974.tb00690.x

Sleight, P. \& Bernardi, L. (1998). Sympathovagal Balance. Circulation, 98 (23), 2640. doi: 10.1161/01.CIR.98.23.2640

Snow, R. (1989). Aptitude-Treatment Interaction as a framework for research on individual differences in learning. In P. Ackerman, R. J. Sternberg, \& R. Glaser (eds.), Learning and Individual Differences, (pp. 13-59). New York: Freeman.

Spangler G., Pekrun, R., Kramer, K., \& Hofmann, H. (2002). Students' Emotions, Physiological Reactions, and Coping in Academic Exams. Anxiety, Stress, \& Coping: An International Journal, 15 (4), 413-432. doi: 10.1080/1061580021000056555

Spielberger, C. D. (1989). State-Trait Anxiety Inventory: Bibliography (2nd ed.). Palo Alto, CA: Consulting Psychologists Press.

SPSS (2005). Linear Mixed-Effects Modeling in SPSS: An Introduction to the MIXED Procedure. Armonk, New York: IBM. Retrieved from http://www.spss.ch/upload/1126184451_Linear\%20Mixed\%20Effects-\%20Modeling\%20in\%20SPSS.pdf.

Stadler, T., Evans, Ph., Hucklebridge, F., \& Clow, A. (2011). Associations between the cortisol awaking response and heart rate variability. Psychoneuroendocrinology, 36 (4), 454-462. doi: 10.1016/j.psyneuen.2010.07.020

Sweller, J. (1988). Cognitive Load During Problem Solving: Effects on Learning. Cognitive Science, 12 (2), 257-285. doi: 10.1207/s15516709 $\operatorname{cog} 1202 \_4$

Sweller, J. (1994). Cognitive Load Theory, Learning Difficulty, and Instructional Design. Learning and Instruction, 4 (4), 295-312. doi: 10.1016/0959-4752(94)90003-5

Sweller, J., Ayres, P., \& Kalyuga, S. (2011). Cognitive Load Theory. New York: Springer.

Takahashi, T., Ikeda, K., Ishikawa, M., Kitamura, N., Tsukasaki, T., Nakama, D., \& Kameda, T. (2005). Anxiety, reactivity, and social stress-induced cortisol elevation in humans. Neuroendocrinology Letters, 26 (4), 351-354.

Twisk, J. W. R. (2006). Applied Multilevel Analysis. A Practical Guide. Cambridge: Cambridge University Press.

Vygotskii, L. S. (1978). Mind in Society: The Development of Higher Psychological Processes. Cambridge: Harvard University Press.

Wagner, W., Göllner, R., Helmke, A., Trautwein, U., \& Lüdtke, O. (2013). Construct validity of student perceptions of instructional quality is high, but not perfect: Dimensionality and generalizability of domain-independent assessments. Learning and Instruction, 28, 1-11. doi: 10.1016/j.learninstruc.2013.03.003

Wild, K. P. (2001). Die Optimierung von Videoanalysen durch zeitsynchrone Befragungsdaten aus dem Experience Sampling. In S. v. Aufschnaiter \& M. Wenzel (eds.), Nutzung von Videodaten zur Untersuchung von Lehr-Lern-Prozessen. Aktuelle Methoden empirischer pädagogischer Forschung [Using video data for investigating teaching and learning processes. Current methods of empirical pedagogical research], (pp. 61-74). Münster: Waxmann.

Wild, K. P. \& Krapp, A. (1996). Die Qualität subjektiven Erlebens in schulischen und betrieblichen Lernumwelten: Untersuchungen mit der Erlebens-Stichproben-Methode [The quality of emotional experiences in vocational and company learning environments: Studies with the experience-sampling-method]. Unterrichtswissenschaft, 24 (3), 195-216. 
Wüst, S., Federenko, I., Hellhammer, D. H., \& Kirschbaum, C. (2000). Genetic factors, perceived chronic stress, and the free cortisol response to awakening. Psychoneuroendocrinology, 25 (7), 707-720. doi: 10.1016/S0306-4530(00)00021-4

Wuttke, E. (2000). Lernstrategien im Lernprozeß. Analysemethode, Strategieeinsatz und Auswirkungen auf den Lernerfolg [Learning strategies in learning processes: Method of analysis, use of strategies, and effects on learning]. Zeitschrift für Erziehungswissenschaft, 3 (1), 97-110. doi: 10.1007/s11618-000-0007-6.

Yeh, Yu-chu (2012). Aptitude-Treatment Interaction. In N. M. Seel (ed.), Encyclopedia of the Sciences of Learning, (pp. 295-298). New York: Springer.

Yerkes, R. M. \& Dodson, J. D. (1908). The Relation of Strength of Stimulus to Rapidity of HabitFormation. Journal of Comparative Neurology and Psychology, 18 (5), 459-482. doi: $10.1002 /$ cne. 920180503 .

Zierer, K. \& Seel, N. M. (2012). General Didactics and Instructional Design: eyes like twins. A transatlantic dialogue about similarities and differences, about the past and the future of two sciences of learning and teaching. Springerplus, 17, 1-15. doi: 10.1186/2193-1801-1-155. 